\title{
G scmem \\ The association between the health-related physical fitness and inhibitory control in preschool children
}

Yiyan Li

School of Kinesiology, Shanghai University of Sport, Shanghai

\section{Tang Zhou}

School of Kinesiology, Shanghai University of Sport, Shanghai

\section{Menghao Sang}

School of Kinesiology, Shanghai University of Sport, Shanghai

Yanhua Lu

School of Kinesiology, Shanghai University of Sport, Shanghai

Jiajia Liu

School of Kinesiology, Shanghai University of Sport, Shanghai

Xiaolong He

School of Physical Education and Health Science, Zhejiang Normal University, Jinhua 321004

Minghui Quan ( $\nabla$ quanminghui@163.com )

School of Kinesiology, Shanghai University of Sport, Shanghai

\section{Research Article}

Keywords: Preschool children, Health-related physical fitness, Flanker task, Inhibitory control, Reaction time

Posted Date: June 28th, 2021

DOI: https://doi.org/10.21203/rs.3.rs-628688/v1

License: (c) (i) This work is licensed under a Creative Commons Attribution 4.0 International License. Read Full License

Version of Record: A version of this preprint was published at BMC Pediatrics on February 24th, 2022. See the published version at https://doi.org/10.1186/s12887-022-03163-y. 


\section{Abstract \\ Background}

Inhibitory control develops rapidly during the preschool stage, and development of inhibitory control in this period is significant for the healthy growth of the future. However, most studies paid more attention to children and adolescents in recent years, but less focus on preschool children. Therefore, the purpose of this study was to explore the association between the health-related physical fitness and inhibitory control in preschool children.

\section{Methods}

This study was a cross-sectional study, 128 preschool children in Yangpu District of Shanghai were recruited by convenient sampling. The health-related physical fitness T-score (HPFT) was obtained by adding standard scores of six indicators: body mass index, handgrip strength, standing long jump, oneleg balance, $2 \times 10 \mathrm{~m}$ shuttle run test, and $20 \mathrm{~m}$ shuttle run test. Inhibitory control was assessed using the flanker task and reflected by reaction time and accuracy.

\section{Results}

A total of 120 preschoolers were included in the final statistical analysis. After adjusting the confounders, HPFT was associated with reaction time $(\beta=-2.49 \mathrm{~ms}, 95 \% \mathrm{Cl}:-4.22,-0.75)$. Similarly, a negative association was observed between one-leg balance and reaction time $(\beta=-12.04 \mathrm{~ms}, 95 \% \mathrm{Cl}$ : $-18.94,-5.15)$, and between $20 \mathrm{~m}$ shuttle run and reaction time $(\beta=-23.28 \mathrm{~ms}, 95 \% \mathrm{Cl}:-37.00,-9.56)$. Compared with the participants in the lowest tertile, HPFT ( $\beta=-158.74,95 \% \mathrm{Cl}$ : $-309.63,-7.84)$, one-leg balance $(\beta=-267.25 \mathrm{~ms}$, $95 \% \mathrm{Cl}:-420.71,-113.79)$ and $20 \mathrm{~m}$ shuttle run $(\beta=-215.58 \mathrm{~ms}, 95 \% \mathrm{Cl}:-374.67,-56.49)$ were all negatively associated with reaction time of those in the highest tertile.

\section{Conclusion}

In addition, there was a non-linear relationship between HPFT and reaction time $(\beta=-3.46 \mathrm{~ms}, 95 \% \mathrm{Cl}$ : -5.39 , -1.53) when HPFT > 249. In conclusion, in order to improve the inhibitory control, it's suggested that HPFT of preschoolers should be at least 249 .

\section{Background}

Executive functions (EFs), a subset of advanced cognitive functions that coordinate with each other to complete complex cognitive tasks, mainly include inhibitory control, working memory, and cognitive flexibility $[1,2]$. Inhibitory control is the core of EFs, which refers to the ability of individuals to inhibit dominant behaviors unrelated to current tasks. People with good inhibitory control can overcome strong 
instinctive tendencies and resist external temptations by controlling attention, behaviors, thoughts, and/or emotions [3]. The good development of inhibitory control contributes to future intellectual development, academic performance, and health status $[4,5]$. However, inhibitory control of developmental dysplasia not only leads to learning disabilities, but also produces a series of behavioral and emotional problems such as attention deficit hyperactivity disorder (ADHD), destructive behavior disorder (DBD), and autism $[6,7]$. A meta-analysis has shown that children with ADHD and DBD perform poorly in inhibitory control [8]. The preschool stage is the golden period for the development of inhibitory control [9]. Therefore, how to promote the development of preschool children's inhibitory control is significant for public health.

Health-related Physical Fitness (HPF) refers to the ability to focus on daily activities, which is an important indicator for evaluating physical and mental health [10]. HPF is composed of cardiorespiratory fitness, musculoskeletal fitness, motor fitness, and body composition [11]. Children with better HPF have higher attention system efficiency, prefrontal cortex activation and executive function[12,13]. Previous studies have shown that HPF is associated with inhibitory control. However, most studies paid more attention to children and adolescents $[13,14]$. For preschool children with the rapid development of inhibitory control, the relationship between HPF and inhibitory control is rarely studied.

Therefore, the purpose of this study is to explore the relationships between the components of HPF and inhibitory control. The findings of this study can serve as a foundation for HPF to help the development of inhibitory control in the preschool stage. According to previous research [15], HPF and inhibitory control in preschool children were hypothesized negatively associated with a certain dose-effect relationship herein.

\section{Methods}

\section{Participants}

This study was a cross-sectional design. Data were from an observational study, entitled 'The effect and mechanism of aerobic exercise on EFs in preschool children: randomized controlled and imaging studies (ChiCTR1900021552, Registered 27 February, 2019, http://www.chictr.org.cn/index.aspx)'. The inclusion criteria were as follows: 1 ) preschool children aged 3-6 years old; 2 ) physically healthy and no contraindications to exercise, such as cardiovascular diseases or neurological diseases; 3 ) voluntary participation (parents or legal guardian signed informed consent). The observational study was approved by the ethics committee of Shanghai University of Sport (ethics committee code: 2017023).

\section{Measurements}

\section{Basic information}

The basic information of the participants was obtained through a questionnaire filled out by the participants' parents or legal guardians, including the participants' age, sex, mother's education (Below high school, Junior high school, Senior high school, College/Associate degree, Bachelor's degree, and 
Master's degree/Doctor's degree), and household income (<9,000RMB, 9,000-30,000RMB, 30,000100,000RMB, > 100,000RMB), etc.

\section{Measurement of HPF}

The measurement of HPF was according to the Chinese National Physical Fitness Measurement Standards Manual-preschool children version (CPFS-preschool) [16], including cardiorespiratory fitness (20m shuttle run test, SRT), musculoskeletal fitness (handgrip strength and standing long jump), motor fitness (One-leg balance and 2×10 m SRT), and body composition (body mass index, BMI). The specific test methods are as follows:

(1) Cardiorespiratory fitness

Cardiorespiratory fitness reflects the overall ability of cardiovascular and respiratory systems to provide oxygen during sustained physical activity (PA) [17]. The most common cardiorespiratory fitness test is $20 \mathrm{~m}$ SRT [6]. During the test, an tester led children to jog back and forth at an increasing speed (starting with a speed of $8.5 \mathrm{~km} / \mathrm{h}$ and increasing $0.5 \mathrm{~km} / \mathrm{h}$ every minute) with the music rhythm between the lines 20 meters apart until they were too tired to reach the end line. The test was conducted once, and the total number of round trips was recorded.

(2) Musculoskeletal fitness

Musculoskeletal fitness is the ability to maintain movement through muscle contraction against resistance [18], commonly assessed by handgrip strength and standing long jump [19]. As for the handgrip strength test, children were naturally standing, and their arms of the test side were stretched out straightly about $10^{\circ}$ apart from the body. T.K.K.5401 (Takei, Niigata, Japan) was used for the test, and the handgrip length was adjusted to the best position according to children's hand length [20]. As for the Standing long jump, children's feet open to the same width as shoulders, standing behind the marking line, bending their knees and swinging their arms to jump forward. The two tests were measured twice, and the maximum values were recorded in kilograms (precision of $0.1 \mathrm{~kg}$ ) and centimeters (precision of $0.1 \mathrm{~cm})$, respectively.

\section{(3) Motor fitness}

Motor fitness refers to the physical quality related to sports performance and sports function, which is composed of the speed/agility quality and the balance quality [11]. One-leg balance is a reliable indicator of the balanced quality for preschool children [11]. The tester held the stopwatch, gave the starting order, and timed from the time the tested child lifted one foot from the ground till when the lifted foot touched the ground. The speed/agile quality of preschool children was evaluated by $2 \times 10 \mathrm{~m} \mathrm{SRT}$, which has been adopted in China since 2003[21]. Children were led by an tester, who ran as fast as possible from the starting point to the end point ( $10 \mathrm{~m}$ apart) back and forth. Testers used a stopwatch to time. The test was measured twice, the shortest time as the final result recorded in seconds (precision of $0.1 \mathrm{~s}$ ). 
(4) Body composition

The height and weight of the participants were measured by the CPFS-preschool, and BMI $\left(\mathrm{BMI}=\mathrm{kg} / \mathrm{m}^{2}\right)$ was calculated. BMI was graded according to the criteria established by the Chinese Working Group on Obesity for Children [22], and the standard score of BMI was calculated according to the scoring criteria [16].

\section{Measurement of inhibitory control}

Flanker Task can objectively evaluate inhibitory control in preschool children [23]. This study used the Fish flanker task (FFT)in E-Prime software to investigate the inhibitory control.

Before the formal test, there was a practice aimed to familiarize the participants with the test process, and require them to achieve more than $80 \%$ accuracy before entering the formal test. The formal test was repeated 3 times, 40 judgments each time. Considering that the participants were younger, they were guided by professionals during the test. The instructions were as follows: "There are five small fishes swimming in the water on the screen, but the middle fish is hungry. You can feed them with the button in your hand. When the middle fish swims to the left, you click the left button. When the middle fish swims to the right, you click the right button". At the beginning of the test, a set of stimulus pictures (Fig. 1) would appear randomly on the screen; pictures were divided into congruent conditions (the direction of all the fishes were the same) and incongruent conditions (the direction of the middle fish is different from the other fish). Participants immediately pressed the button after judging. If participants press the wrong button, or RT was less than $200 \mathrm{~ms}$ or more than $3 \mathrm{~s}$, it would be judged as an invalid reaction, not included in statistical analysis. The formal test included 120 conditions (60 congruent conditions and 60 incongruent conditions). Two types of stimuli appeared at random with the same probability. The participants had a 10 s rest after every 40 judgments. The tests were completed one-on-one by an adult tester and participant in a quiet kindergarten classroom, and reaction time (RT) and accuracy (ACC) of each test were directly recorded on the software.

\section{Statistical analysis}

Continuous variables and categorical variables are presented as mean, standard deviation (SD), or percentages. The values beyond Mean $\pm 3 S D$ are considered as outliers and removed from the final analysis. The scores of each index are converted into standardized scores with a mean of 50 and SD of 10. BMI was scored and graded according to the CPFS-preschool. Because $2 \times 10 \mathrm{~m} \mathrm{SRT} \mathrm{is} \mathrm{negatively}$ associated with the speed/agility, the score was multiplied by -1 and then standardized. The HPF standard score formula is $T=[(X-M) / S D] \times 10+50(X:$ personal performance, $M$ : mean). The sum of each

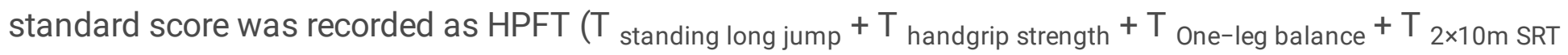
$\left.+\mathrm{T}_{20 \mathrm{~m} \mathrm{SRT}}+\mathrm{T}_{\mathrm{BMI}}\right)$.

Firstly, the relationship between HPFT and inhibitory control (ACC and RT) was tested by a multiple linear regression model. With continuous variables and categorical variables as independent variables and 
inhibitory control as dependent variables, HPFT showed the relationship between ACC and RT after adjusting age, sex, mother's education, and household income. Secondly, piecewise linear regression analysis was used to test whether there is a non-linear relationship between HPFT and inhibitory control. The $\mathrm{R}$ language-based Empower Stats software was used for statistical analysis. $\mathrm{P}<0.05$ was considered statistically significant.

\section{Result}

\section{Basic Information}

A total of 128 preschool children were recruited from four kindergartens in Yangpu District. Two children were excluded because of inclusion criteria, and six children were excluded because of missing data or outliers. Finally, 120 children were included in the statistical analysis ( 66 boys and 54 girls, with an average age of $4.88 \pm 0.38$ years old) (Fig. 2).

The height, weight, and BMI of boys were significantly higher than girls, while there was no significant gender difference in demographic information such as mother's education and household income. No significant gender difference was observed between HPFT and inhibitory control. Among the indicators of physical fitness, the handgrip strength of boys was significantly higher than that of girls $(P<0.01)$, and the one-leg balance of girls was significantly higher than that of boys $(P<0.01)$. In addition, other indicators had no significant difference between boys and girls (Table 1). 
Table 1

Basic information for the participants

\begin{tabular}{|lllll|}
\hline Characteristics & Boys $(\mathrm{n}=66)$ & Girls $(\mathrm{n}=\mathbf{5 4})$ & Total $(\mathrm{n}=120)$ & $\begin{array}{c}P \text { for } \\
\text { sex }\end{array}$ \\
\hline $\begin{array}{l}\text { Anthropometric } \\
\text { characteristics }\end{array}$ & & & & \\
\hline Age (years) & $4.85 \pm 0.36$ & $4.92 \pm 0.41$ & $4.88 \pm 0.38$ & 0.324 \\
\hline Height (cm) & $111.73 \pm 4.95$ & $109.57 \pm 4.52$ & $110.76 \pm 4.86$ & $\mathbf{0 . 0 2 7}$ \\
\hline Weight (kg) & $20.40 \pm 3.44$ & $18.41 \pm 2.40$ & $19.50 \pm 3.16$ & $\mathbf{0 . 0 0 2}$ \\
\hline Inhibitory control & & & & \\
\hline ACC (\%) & $85.91 \pm 13.68$ & $85.32 \pm 14.82$ & $85.65 \pm 14.15$ & 0.752 \\
\hline RT (ms) & $1236.14 \pm$ & $1249.35 \pm$ & $1242.09 \pm$ & 0.975 \\
\hline
\end{tabular}

Socioeconomic status

Mother's education, $\mathrm{n}(\%)$

Below high school

$2(3.12 \%)$

$1(2.08 \%)$

$3(2.68 \%)$

Junior high school

$6(9.38 \%)$

$4(8.33 \%)$

$10(8.93 \%)$

Senior high school

$12(18.75 \%)$

$11(22.92 \%)$

$23(20.54 \%)$

College/associate degree

$34(53.12 \%)$

27 (56.25\%)

$61(54.46 \%)$

B.D.

$10(15.62 \%)$

$5(10.42 \%)$

15 (13.39\%)

M.D. / Ph.D.

$2(3.12 \%)$

$1(2.08 \%)$

$3(2.68 \%)$

Household income

(RMB/year)

$<9000$

9000-30,000

$30,000-100,000$

$>100,000$

Body composition

BMI $\left(\mathrm{kg} / \mathrm{m}^{2}\right)$

Normal
$16.29 \pm 2.14$

$47(71.21 \%)$
$4(8.33 \%)$

7 (14.58\%)

$18(37.50 \%)$

19 (39.58\%)

$28(43.75 \%)$

$13(20.31 \%)$

$19(29.69 \%)$

$28(43.75 \%)$

$19(39.58 \%)$

$15.29 \pm 1.29$

$44(84.62 \%)$
$8(7.14 \%)$

$20(17.86 \%)$

37 (33.04\%)

47 (41.96\%)

$15.84 \pm 1.87$

0.015

91 (77.12\%)

Note: Continuous variables are resented as mean \pm standard deviation, and classified variables are resented as percentage (\%). Statically significant values are in bold. 


\begin{tabular}{|c|c|c|c|c|}
\hline Characteristics & Boys $(n=66)$ & Girls(n = 54) & Total $(n=120)$ & $\begin{array}{l}P \text { for } \\
\text { sex }\end{array}$ \\
\hline Overweight & $6(9.09 \%)$ & $8(15.38 \%)$ & $14(11.86 \%)$ & \\
\hline Obesity & $13(19.70 \%)$ & $0(0.00 \%)$ & $13(11.02 \%)$ & \\
\hline \multicolumn{5}{|l|}{ Musculoskeletal fitness } \\
\hline Handgrip strength(kg) & $6.15 \pm 2.18$ & $4.88 \pm 2.10$ & $5.58 \pm 2.23$ & 0.001 \\
\hline Standing long jump (cm) & $85.65 \pm 15.68$ & $85.34 \pm 12.14$ & $85.06 \pm 14.15$ & 0.555 \\
\hline \multicolumn{5}{|l|}{ Motor fitness } \\
\hline One-leg balance(s) & $10.25 \pm 8.26$ & $14.75 \pm 9.79$ & $12.27 \pm 9.22$ & 0.003 \\
\hline $2 \times 10 \mathrm{~m}$ SRT (s) & $7.30 \pm 0.80$ & $7.35 \pm 0.73$ & $7.32 \pm 0.77$ & 0.642 \\
\hline \multicolumn{5}{|l|}{ Cardiorespiratory fitness } \\
\hline 20m SRT (laps) & $13.85 \pm 4.67$ & $13.19 \pm 3.74$ & $13.55 \pm 4.27$ & 0.430 \\
\hline HPFT & $299.62 \pm 36.59$ & $298.74 \pm 32.86$ & $299.22 \pm 34.82$ & 0.800 \\
\hline
\end{tabular}

\section{Relationship between HPFT and inhibitory control - results of multiple regression analysis}

No significant interactions were found between HPFT and gender ( $P$ for interaction $=0.12$ ), so boys and girls were combined for statistical analyses. There was a negative association between HPFT and RT in the multiple linear regression results ( $\beta=-2.49,95 \% \mathrm{Cl}:-4.22,-0.75)$, after adjusting for age, sex, mother's education, and household income. In addition, after adjusting confounding factors, for $1 \mathrm{sec}$ and 1 lap increased in one-leg balance and 20m SRT, RT reduced by $12.04 \mathrm{~ms}(\beta=12.04,95 \% \mathrm{Cl}:-18.94,-5.15)$ and $23.28 \mathrm{~ms}(\beta=23.28,95 \% \mathrm{Cl}:-37.00,-9.56)$, respectively.

The results of categorized linear regression showed that when HPFT were divided into three groups (T1T3, T1 was the lowest). Compared with the T1 group, RT of the T3 group reduced by $158.74 \mathrm{~ms}$ $(\beta=-158.74,95 \% \mathrm{Cl}:-420.71,-113.79)$. RT was negatively associated with one leg-balance $(\beta=-267.25$, $95 \% \mathrm{Cl}:-18.94,-5.15)$ and $20 \mathrm{~m}$ SRT $(\beta=-215.58,95 \% \mathrm{Cl}$ - $374.67,-56.49)$, after adjusted the confounding factors (Table 2). 
Table 2

Associations of HPF and Inhibitory control in preschool children

\begin{tabular}{|c|c|c|c|c|}
\hline \multirow[t]{2}{*}{ HPF } & \multicolumn{2}{|c|}{ Accuracy, $\beta(95 \% \mathrm{Cl})$} & \multicolumn{2}{|c|}{ Reaction time, $\beta(95 \% \mathrm{Cl})$} \\
\hline & Model 1 & Model 2 & Model 1 & Model 2 \\
\hline \multicolumn{5}{|l|}{$\begin{array}{l}\text { Musculoskeletal } \\
\text { fitness }\end{array}$} \\
\hline Handgrip strength (kg) & $\begin{array}{l}0.06(-1.09 \\
1.21)\end{array}$ & $\begin{array}{l}-0.80(-2.01 \\
0.41)\end{array}$ & $\begin{array}{l}-17.54(-41.64 \\
6.56)\end{array}$ & $\begin{array}{l}-17.76(-46.27 \\
10.75)\end{array}$ \\
\hline \multicolumn{5}{|l|}{$\begin{array}{l}\text { Handgrip strength- } \\
\text { tertile (kg) }\end{array}$} \\
\hline $\mathrm{T} 1(1.00-4.50)$ & REF. & REF. & REF. & REF. \\
\hline $\mathrm{T} 2(4.60-5.75)$ & $\begin{array}{l}-0.96(-7.64 \\
5.72)\end{array}$ & $\begin{array}{l}-2.97(-9.65 \\
3.70)\end{array}$ & $\begin{array}{l}-65.54(-206.98 \\
75.90)\end{array}$ & $\begin{array}{l}-74.27(-231.42, \\
82.87)\end{array}$ \\
\hline T3(6.00-12.00) & $\begin{array}{l}1.07(-4.88 \\
7.02)\end{array}$ & $\begin{array}{l}-3.34(-9.72 \\
3.03)\end{array}$ & $\begin{array}{l}-40.41(-166.37 \\
85.55)\end{array}$ & $\begin{array}{l}-39.76(-189.78 \\
110.27)\end{array}$ \\
\hline$P$ for trend & 0.70 & 0.32 & 0.55 & 0.65 \\
\hline $\begin{array}{l}\text { Standing long jump } \\
\text { (cm) }\end{array}$ & $\begin{array}{l}0.11(-0.07 \\
0.29)\end{array}$ & $\begin{array}{l}0.03(-0.15 \\
0.21)\end{array}$ & $-3.56(-7.33,0.21)$ & $-3.51(-7.60,0.58)$ \\
\hline \multicolumn{5}{|l|}{$\begin{array}{l}\text { Standing long jump- } \\
\text { tertile }(\mathrm{cm})\end{array}$} \\
\hline T1(47.00-81.00) & REF. & REF. & REF. & REF. \\
\hline T2(81.20-90.40) & $\begin{array}{l}5.93(-0.23 \\
12.09)\end{array}$ & $\begin{array}{l}2.59(-3.81 \\
8.98)\end{array}$ & $\begin{array}{l}-76.40(-207.10 \\
54.30)\end{array}$ & $\begin{array}{l}-62.52(-211.50 \\
86.46)\end{array}$ \\
\hline T3(91.00-118.00) & $\begin{array}{l}3.03(-3.13 \\
9.19)\end{array}$ & $\begin{array}{l}-0.45(-6.63 \\
5.72)\end{array}$ & $\begin{array}{l}-124.56(-255.26 \\
6.14)\end{array}$ & $\begin{array}{l}-123.00(-266.81 \\
20.81)\end{array}$ \\
\hline$P$ for trend & 0.34 & 0.86 & 0.06 & 0.10 \\
\hline \multicolumn{5}{|l|}{ Motor fitness } \\
\hline One-leg balance (s) & $\begin{array}{l}0.14(-0.13 \\
0.42)\end{array}$ & $\begin{array}{l}0.09(-0.22 \\
0.40)\end{array}$ & $\begin{array}{l}-8.62(-14.28 \\
-2.95)\end{array}$ & $\begin{array}{l}-12.04(-18.94 \\
-5.15)\end{array}$ \\
\hline \multicolumn{5}{|l|}{$\begin{array}{l}\text { One-leg balance-tertile } \\
\text { (s) }\end{array}$} \\
\hline $\mathrm{T} 1(1.80-7.60)$ & REF. & REF. & REF. & REF. \\
\hline $\mathrm{T} 2(7.70-13.00)$ & $\begin{array}{l}0.30(-5.76 \\
6.37)\end{array}$ & $\begin{array}{l}-0.37(-6.41 \\
5.66)\end{array}$ & $\begin{array}{l}-64.02(-190.94 \\
62.90)\end{array}$ & $\begin{array}{l}-78.86(-215.49 \\
57.78)\end{array}$ \\
\hline
\end{tabular}




\begin{tabular}{|c|c|c|c|c|}
\hline \multirow[t]{2}{*}{ HPF } & \multicolumn{2}{|c|}{ Accuracy, $\beta(95 \% \mathrm{Cl})$} & \multicolumn{2}{|c|}{ Reaction time, $\beta(95 \% \mathrm{Cl})$} \\
\hline & Model 1 & Model 2 & Model 1 & Model 2 \\
\hline T3(13.10-49.40) & $\begin{array}{l}7.34(1.27 \\
13.41)\end{array}$ & $\begin{array}{l}5.82(-0.96 \\
12.60)\end{array}$ & $\begin{array}{l}-208.11(-335.03, \\
-81.19)\end{array}$ & $\begin{array}{l}-267.25(-420.71 \\
-113.79)\end{array}$ \\
\hline$P$ for trend & 0.02 & 0.11 & $<0.05$ & $<0.05$ \\
\hline $2 \times 10 \mathrm{~m} \mathrm{SRT}\left(\mathrm{s}^{-1}\right)$ & $\begin{array}{l}2.93(-0.34 \\
6.21)\end{array}$ & $\begin{array}{l}0.66(-2.71 \\
4.03)\end{array}$ & $\begin{array}{l}-50.82(-120.64 \\
19.00)\end{array}$ & $\begin{array}{l}-53.42(-132.07 \\
25.24)\end{array}$ \\
\hline \multicolumn{5}{|c|}{$2 \times 10 \mathrm{~m}$ SRT-tertile $\left(\mathrm{s}^{-1}\right)$} \\
\hline T1(-9.21--7.58) & REF. & REF. & REF. & REF. \\
\hline T2(-7.55--6.90) & $\begin{array}{l}2.95(-3.27 \\
9.17)\end{array}$ & $\begin{array}{l}0.58(-5.64 \\
6.80)\end{array}$ & $\begin{array}{l}68.39(-60.53 \\
197.31)\end{array}$ & $\begin{array}{l}39.89(-104.04 \\
183.83)\end{array}$ \\
\hline T3(-6.88--5.80) & $\begin{array}{l}3.13(-3.09 \\
9.35)\end{array}$ & $\begin{array}{l}-0.52(-7.12 \\
6.07)\end{array}$ & $\begin{array}{l}-103.14(-232.06 \\
25.78)\end{array}$ & $\begin{array}{l}-95.65(-248.24 \\
56.94)\end{array}$ \\
\hline$P$ for trend & 0.32 & 0.89 & 0.12 & 0.26 \\
\hline (continues) & & & & \\
\hline
\end{tabular}


Table 2

(Continued)

\begin{tabular}{|c|c|c|c|c|}
\hline \multirow[t]{2}{*}{ HPF } & \multicolumn{2}{|c|}{ Accuracy, $\beta(95 \% \mathrm{Cl})$} & \multicolumn{2}{|c|}{ Reaction time, $\beta(95 \% \mathrm{Cl})$} \\
\hline & Model 1 & Model 2 & Model 1 & Model 2 \\
\hline \multicolumn{5}{|l|}{$\begin{array}{l}\text { Cardiorespiratory } \\
\text { fitness }\end{array}$} \\
\hline 20m SRT (laps) & $\begin{array}{l}0.58(-0.01 \\
1.16)\end{array}$ & $\begin{array}{l}0.18(-0.44 \\
0.79)\end{array}$ & $\begin{array}{l}-21.90(-33.96 \\
-9.85)\end{array}$ & $\begin{array}{l}-23.28(-37.00 \\
-9.56)\end{array}$ \\
\hline $\mathrm{T} 1(5.00-10.00)$ & REF. & REF. & REF. & REF. \\
\hline T2(11.00-13.00) & $\begin{array}{l}7.80(1.13 \\
14.47)\end{array}$ & $\begin{array}{l}4.39(-2.91 \\
11.70)\end{array}$ & $\begin{array}{l}-61.70(-201.01 \\
77.62)\end{array}$ & $\begin{array}{l}-56.11(-221.69 \\
109.46)\end{array}$ \\
\hline T3(14.00-25.00) & $\begin{array}{l}6.07(-0.20 \\
12.33)\end{array}$ & $\begin{array}{l}1.46(-5.56 \\
8.48)\end{array}$ & $\begin{array}{l}-193.71(-324.49, \\
-62.93)\end{array}$ & $\begin{array}{l}-215.58(-374.67 \\
-56.49)\end{array}$ \\
\hline$P$ for trend & 0.10 & 0.92 & $<0.05$ & $<0.05$ \\
\hline \multicolumn{5}{|l|}{ Body Composition } \\
\hline BMI (scores) & $\begin{array}{l}-1.23(-2.81, \\
0.36)\end{array}$ & $\begin{array}{l}-2.04(-3.58 \\
-0.50)\end{array}$ & $4.11(-29.79,38.02)$ & $6.25(-31.07,43.57)$ \\
\hline HPFT & $\begin{array}{l}0.04(-0.03 \\
0.12)\end{array}$ & $\begin{array}{l}-0.02(-0.10 \\
0.05)\end{array}$ & $-2.25(-3.75,-0.75)$ & $-2.49(-4.22,-0.75)$ \\
\hline \multicolumn{5}{|l|}{ HPFT-tertile } \\
\hline $\begin{array}{l}\text { T1 (218.45- } \\
280.85)\end{array}$ & REF. & REF. & REF. & REF. \\
\hline $\begin{array}{l}\text { T2 (281.69- } \\
316.54)\end{array}$ & $\begin{array}{l}4.49(-1.70 \\
10.69)\end{array}$ & $\begin{array}{l}2.10(-4.30 \\
8.50)\end{array}$ & $\begin{array}{l}23.90(-103.98 \\
151.77)\end{array}$ & $\begin{array}{l}-10.14(-158.64 \\
138.37)\end{array}$ \\
\hline $\begin{array}{l}\text { T3 (317.13- } \\
376.97)\end{array}$ & $\begin{array}{l}2.25(-3.95 \\
8.45)\end{array}$ & $\begin{array}{l}-3.38(-9.88 \\
3.12)\end{array}$ & $\begin{array}{l}-155.57(-283.45 \\
-27.70)\end{array}$ & $\begin{array}{l}-158.74(-309.63 \\
-7.84)\end{array}$ \\
\hline$P$ for trend & 0.48 & 0.30 & $<0.05$ & $<0.05$ \\
\hline
\end{tabular}

\section{Relationship between HPFT and RT-piecewise linear regression analysis}

Moreover, the piecewise linear regression analysis shows that there is a non-linear relationship between HPFT and RT in preschool children (Fig. 3). After adjusting age, sex, mother's education, and household income, When HPFT is more than 249, for every 1 score of increase in HPFT, RT reduced by $-3.46 \mathrm{~ms}$ ( $\beta=$ $-3.46,95 \% \mathrm{Cl}:-5.39,-1.53$ ) (Table 3). 
Table 3

Threshold effect analysis between HPFT and RT

\begin{tabular}{|lll|}
\hline HPFT & RT $(\boldsymbol{\beta}, 95 \% \mathrm{Cl})$ & \\
\cline { 2 - 3 } & Model 1 & Model 2 \\
\hline$<249$ & $1.92(-1.93,5.77)$ & $13.36(-1.36,28.07)$ \\
$>249$ & $-4.49(-6.91,-2.08)$ & $-3.46(-5.39,-1.53)$ \\
\hline Likelihood Ratio & 0.021 & 0.026 \\
\hline $\begin{array}{l}\text { Model 1: No adjust. Model 2: Adjusting for age, sex, mother's education and household income. } \\
\text { Statically significant values are in bold. }\end{array}$ \\
\hline
\end{tabular}

\section{Discussion}

This study aimed to explore the association between HPFT and inhibitory control in preschool children. A significant dose-effect relationship was observed between HPFT and RT in this study. Besides, one-leg balance and 20m SRT were also negatively associated with RT. In addition, there was a nonlinear relationship between HPFT and RT. When HPFT is greater than 249, RT was significantly reduced.

\section{Comparison of similar research results}

The results of this study indicated that the higher HPF in the preschool stage was, the better RT was, consistent with the results of previous studies $[24,25]$. Cardiorespiratory fitness was most concerned in HPF, which was considered as a significant predictor of inhibitory control [9]. High cardiorespiratory fitness in children is related to better EFs and differences in local brain structure and function [26]. This study also found that preschool children's cardiorespiratory fitness was significantly associated with RT, which was consistent with the results of some studies on children and adolescents [27]. However, most studies focus on children's cardiorespiratory fitness and EFs, but few studies on preschool children. This study further enriches the evidence of such studies.

This study also found that the significant association between motor fitness and RT in preschool children, which was consistent with the results of Marion Stein. At the same time, Marion Stein believes that coordinated exercise can enhance inhibitory control [28]. Yu-Kai Chang's research shows that coordinated exercise intervention with different intensities has a positive effect on preschool children's RT and ACC. In this study, the one-leg balance, an indicator for evaluating exercise adaptability, also showed a negative association with RT. This may because coordinated exercise changes the central cortex of the brain in the cortex and subcortex, and the central cortex involving the motor and sensory system matures earliest, thereby affecting cognition [29]. Long-term coordinated exercise may improve EFs by increasing the allocation of attention resources and accelerating the neural cognitive process [29]. In addition, similar results have been found in children and adolescents that motor fitness was associated with RT [30]. 
In addition, this study has not found the association between musculoskeletal fitness and inhibitory control. Although previous studies have shown that musculoskeletal fitness is beneficial to children's health, including reducing obesity and heart metabolic risk, it is mainly related to strengthening cognitive control and working memory [31]. The existing evidence on musculoskeletal fitness and inhibitory control is insufficient [32]. Therefore, it is necessary to continue to explore this aspect. At the same time, the study found no association between BMI score and inhibitory control. Previous studies have shown that obese children have significantly lower EFs than normal weight children [33]. However, in this study, the majority of participants with normal weight (77.12\%) resulted in a smaller dispersion of BMI, which may be the main reason for the lack of association between BMI and inhibitory control.

An interesting finding was a non-linear relationship between HPFT and RT in preschool children in this study. In other words, when HPFT was greater than 249 , RT was significantly accelerated, and vice versa. It is indicated that the effect of HPF on inhibitory control may need to reach a certain threshold. Similarly, the association between HPF and academic performance had the same findings in the study of children and adolescents. For example, the cardiorespiratory fitness of children in grade 2 and grade 3 (aged $7.8 \pm$ $0.6 y e a r s$ old) of primary school had a non-linear relationship with spelling and mathematics scores. When the score of the 20m SRT was 22-28 laps, the cardiorespiratory fitness had a positive association with spelling and mathematics scores, but there was no significant association between them above 28 laps [34]. There were few reports on the level of HPT in preschool children to achieve the ideal inhibitory control level. Our findings of this study were an important supplement to this research problem.

However, this study did not find the relationship of HPT and its fitness components with ACC. In Marion Stein's study, the improvement of motor fitness, especially the strengthening of coordination ability, will increase ACC [28]. This may because FFT in this study was relatively simple, the overall accuracy was higher $(85.65 \pm 14.15 \%)$, to achieve the ceiling effect, so there was no significant relationship between the two. At present, there are few studies on HPT and ACC of preschool children, and the association between them needs to be further explored.

\section{Possible mechanism of the relationship between HPF and Inhibitory control}

The reasons for the significant relationship between HPF and RT may be as follows. (1) Previous studies have shown that higher HPF level was possibly associated with regular moderate-to-vigorous intensity PA, and engaging in more PA has been confirmed beneficial to EFs by many studies [35]. (2) Increased brain-derived neurotrophic factor (BDNF) and insulin-like growth factor 1 (IGF-1) in the prefrontal cortex triggered by exercise can regulate the network involved in executive function [36]. (3) HPF is closely related to brain structure, and better HPF can promote the growth of brain structural cells, thereby assisting in the development of inhibitory control in the early life [37].

\section{Strengths and limitations}


This study has several strengths. Firstly, our research including four important components of HPF, cardiorespiratory fitness, musculoskeletal fitness, motor fitness and body composition, and not only discusses the relationship between single component and inhibitory control, but also integrates each component of HPF to show its relationship more intuitively by using the form of standardized scores. Secondly, multiple linear regression and piecewise linear regression were used to reveal the dose-effect and non-linear relationship between HPF and inhibitory control.

Several limitations are also worth noting. First, this study used a cross-sectional study design, which cannot make the inference of causality. Second, a convenient sample was recruited from Shanghai Yangpu district, which may limit the popularization of our research results in the population. In the future, it is necessary to increase the sample size and longitudinal studies to verify the relationship between HPF and inhibitory control. Third, in addition to the known potential confounding factors have been controlled, there might still have been other potential confounding effects that were not considered or measured.

\section{Conclusions}

In summary, we identified a significant association between health-related physical fitness and inhibitory control in preschool children, especially when health-related physical fitness T-score was greater than 249. Therefore, improving health-related physical fitness of preschool children is more likely to benefit to the development of inhibitory control. Subsequently, the relationships among health-related physical fitness, executive functions and other fitness components should be further verified.

\section{Abbreviations}

ACC: Accuracy; BMI: Body mass index; B.D.: Bachelor's degree; CPFS-preschool: Chinese National Physical Fitness Measurement Standards Manual-preschool children version; EFs: Executive functions; HPF: Health-related physical fitness; HPFT: Health-related physical fitness T-score; M.D.: Master's degree; PA: Physical activity; Ph.D.: Doctor's degree; RT: Reaction time; SRT: Shuttle run test

\section{Declarations}

\section{Ethics approval and consent to participate}

All procedures were approved by the ethics committee of Shanghai University of Sport (ethics committee code: 2017023). Informed written consent was obtained from parents or legal guardian of all participants.

\section{Consent for publication}

Not applicable.

\section{Availability of data and material}


The data and analysis during the current study are available from the corresponding author on reasonable request.

\section{Competing interests}

The authors declare that they have no competing interests.

\section{Funding}

This research was funded by the National Natural Science Foundation of China (81703252), the National Key Research and Development Program of China (2020YFC2003301, 2020YFC2007005), the Shanghai Sport Bureau (No. 20Q003) and the Shanghai Key Lab of Human Performance (Shanghai University of sport) (No. 11DZ2261100). The funders were not involved in the study design, data collection, data analysis or writing of the manuscript.

\section{Authors' contributions}

Conceptualization: M.Q. Methodology and Investigation and Data collection: M.Q., Y.L., J.L., M.S., YH.L., T.Z., X.H. Data analysis: Y.L. Writing-Original Draft, Review, Editing: Y.L., M.Q. Project administration and Funding acquisition: M.Q.

\section{Acknowledgements}

We thank all the participants and kindergarten very much for their collaboration.

\section{References}

1. Funahashi S: Neuronal mechanisms of executive control by the prefrontal cortex. Neuroscience research 2001, 39(2):147-165. https://doi.org/10.1016/s0168-0102(00)00224-8

2. Zelazo PD: Executive function: Reflection, iterative reprocessing, complexity, and the developing brain. Developmental Review 2015, 38:55-68. https://doi.org/10.1016/j.dr.2015.07.001

3. Wu H, Wang M: Internal Structure of Relationships for Inhibitory Control: A Cognitive Neuroscience Perspective. Chinese J of Clin Psycho 2015, 23:991-995. https://doi.org/10.16128/j.cnki.10053611.2015.06.009

4. Moffitt TE, Arseneault L, Belsky D, Dickson N, Hancox RJ, Harrington H, Houts R, Poulton R, Roberts BW, Ross S et al: A gradient of childhood self-control predicts health, wealth, and public safety. Proc Natl Acad Sci U S A 2011, 108(7):2693-2698. https://doi.org/10.1073/pnas.1010076108

5. Li L, Zhang J, Cao M, Hu W, Zhou T, Huang T, Chen P, Quan M: The effects of chronic physical activity interventions on executive functions in children aged 3-7 years: A meta-analysis. J Sci Med Sport 2020, 23(10):949-954. https://doi.org/10.1016/j.jsams.2020.03.007

6. Schoemaker K, Bunte T, Wiebe SA, Espy KA, Deković M, Matthys W: Executive function deficits in preschool children with ADHD and DBD. J Child Psychol Psychiatry 2012, 53(2):111-119. 
https://doi.org/ 10.1111/j.1469-7610.2011.02468.x

7. Elliott R: Executive functions and their disorders. Br Med Bull 2003.

https://doi.org/10.1093/bmb/65.1.49

8. Morgan AB, Lilienfeld SO: A meta-analytic review of the relation between antisocial behavior and neuropsychological measures of executive function. Clin Psycho Rev 2000, 20(1):113-136.

https://doi.org/10.1016/s0272-7358(98)00096-8

9. Nieto-Lopez M, Sanchez-Lopez M, Visier-Alfonso ME, Martinez-Vizcaino V, Jimenez-Lopez E, AlvarezBueno C: Relation between physical fitness and executive function variables in a preschool sample. Pediatr Res 2020, 88(4):623-628. https://doi.org/ 10.1038/s41390-020-0791-z

10. Ortega FB, Ruiz JR, Castillo MJ, Sjostrom M: Physical fitness in childhood and adolescence: a powerful marker of health. Int J Obes (Lond) 2008, 32(1):1-11.

https://doi.org/10.1038/sj.ijo.0803774

11. Ortega FB, Cadenas-Sanchez C, Sanchez-Delgado G, Mora-Gonzalez J, Martinez-Tellez B, Artero EG, Castro-Pinero J, Labayen I, Chillon P, Lof M et al: Systematic review and proposal of a field-based physical fitness-test battery in preschool children: the PREFIT battery. Sports Med 2015, 45(4):533555. https://doi.org/10.1007/s40279-014-0281-8

12. Hogan $M$, Kiefer $M$, Kubesch $S$, Collins $P$, Kilmartin $L$, Brosnan $M$ : The interactive effects of physical fitness and acute aerobic exercise on electrophysiological coherence and cognitive performance in adolescents. Exp Brain Res 2013, 229(1):85-96. https://doi.org/ 10.1007/s00221-013-3595-0

13. Tomporowski PD, Davis CL, Miller PH, Naglieri JA: Exercise and Children's Intelligence, Cognition, and Academic Achievement. Educ Psychol Rev 2008, 20(2):111-131. https://doi.org/ 10.1007/s10648007-9057-0

14. van der Niet AG, Smith J, Scherder EJ, Oosterlaan J, Hartman E, Visscher C: Associations between daily physical activity and executive functioning in primary school-aged children. J Sci Med Sport 2015, 18(6):673-677. https://doi.org/10.1016/j.jsams.2014.09.006

15. Donnelly JE, Hillman CH, Castelli D, Etnier JL, Lee S, Tomporowski P, Lambourne K, Szabo-Reed AN: Physical Activity, Fitness, Cognitive Function, and Academic Achievement in Children: A Systematic Review. Medicine and science in sports and exercise 2016, 48(6):1197-1222. https://doi.org/10.1249/MSS.0000000000000901

16. The General Administration of Sport of China: The National Physical Fitness Measurement Standards Manual, Preschool Children Version. Beijing,China: People's Physical Education Press; 2003.

17. Taylor HL, Buskirk E, Henschel A: Maximal oxygen intake as an objective measure of cardiorespiratory performance. J App/ Physio/ 1955, 8(1):73-80. https://doi.org/10.1152/jappl.1955.8.1.73

18. Tsai Y-J, Huang C-J, Hung C-L, Kao S-C, Lin C-F, Hsieh S-S, Hung T-M: Muscular fitness, motor competence, and processing speed in preschool children. European Journal of Developmental Psychology 2019, 17(3):415-431. https://doi.org/10.1080/17405629.2019.1661835 
19. Ruiz JR, Castro-Pinero J, Espana-Romero V, Artero EG, Ortega FB, Cuenca MM, Jimenez-Pavon D, Chillon $\mathrm{P}$, Girela-Rejon MJ, Mora $\mathrm{J}$ et al: Field-based fitness assessment in young people: the ALPHA health-related fitness test battery for children and adolescents. Br J Sports Med 2011, 45(6):518524. https://doi.org/10.1136/bjsm.2010.075341

20. Sanchez-Delgado G, Cadenas-Sanchez C, Mora-Gonzalez J, Martinez-Tellez B, Chillón P, Löf M, Ortega FB, Ruiz JR: Assessment of handgrip strength in preschool children aged 3 to 5 years. The Journal of hand surgery, European volume 2015, 40(9):966-972. https://doi.org/10.1177/1753193415592328

21. The General Administration of Sport of China. The National Physical Fitness Measurement Standards Manual; Preschool Children V ersion; People's Physical Education Press: Beijing, China, 2003. https://doi.org/10.1177/1753193415592328

22. Li H, Zong X, Ji C, Mi J: Body mass index cut-offs for overweight and obesity in Chinese children and adolescents aged 2-18 years. Chinese J Epidemiol 2010(06):616-620.

23. Christ SE, Kester LE, Bodner KE, Miles JH: Evidence for selective inhibitory impairment in individuals with autism spectrum disorder. Neuropsychology 2011, 25(6):690-701.

https://doi.org/10.1037/a0024256

24. Kamijo K, Pontifex MB, Khan NA, Raine LB, Scudder MR, Drollette ES, Evans EM, Castelli DM, Hillman $\mathrm{CH}$ : The association of childhood obesity to neuroelectric indices of inhibition. Psychophysiology 2012, 49(10):1361-1371. https://doi.org/10.1037/a0024256

25. Chen X, Wang R, Shi X, Zhu X: Influence of Physical Activity and Fitness on Adolescents' s Cognitive Function and Academic Performance. Sports Res Edu 2020, 35(03):81-88.

https://doi.org/10.16207/j.cnki.2095-235x.2020.03.014

26. Hillman $\mathrm{CH}$, Buck SM, Themanson JR, Pontifex MB, Castelli DM: Aerobic fitness and cognitive development: Event-related brain potential and task performance indices of executive control in preadolescent children. Dev Psychol 2009, 45(1):114-129. https://doi.org/10.1037/a0014437

27. Khan NA, Hillman $\mathrm{CH}$ : The relation of childhood physical activity and aerobic fitness to brain function and cognition: a review. Pediatr Exerc Sci 2014, 26(2):138-146. https://doi.org/10.1123/pes.2013-0125

28. Stein M, Auerswald M, Ebersbach M: Relationships between Motor and Executive Functions and the Effect of an Acute Coordinative Intervention on Executive Functions in Kindergartners. Frontiers in psychology 2017, 8:859. https://doi.org/10.3389/fpsyg.2017.00859

29. Chang YK, Tsai YJ, Chen TT, Hung TM: The impacts of coordinative exercise on executive function in kindergarten children: an ERP study. Exp Brain Res 2013, 225(2):187-196. https://doi.org/10.1007/s00221-012-3360-9

30. Moradi A, Sadri Damirchi E, Narimani M, Esmaeilzadeh S, Dziembowska I, Azevedo LB, Luiz do Prado W: Association between Physical and Motor Fitness with Cognition in Children. Medicina (Kaunas) 2019, 55(1). https://doi.org/10.3390/medicina55010007 
31. Smith JJ, Eather N, Morgan PJ, Plotnikoff RC, Faigenbaum AD, Lubans DR: The health benefits of muscular fitness for children and adolescents: a systematic review and meta-analysis. Sports Med 2014, 44(9):1209-1223. https://doi.org/10.1007/s40279-014-0196-4

32. Mora-Gonzalez J, Esteban-Cornejo I, Solis-Urra P, Migueles JH, Cadenas-Sanchez C, Molina-Garcia P, Rodriguez-Ayllon M, Hillman $\mathrm{CH}$, Catena A, Pontifex MB et al: Fitness, physical activity, sedentary time, inhibitory control, and neuroelectric activity in children with overweight or obesity: The ActiveBrains project. Psychophysiology 2020, 57(6):e13579. https://doi.org/10.1111/psyp.13579

33. Mora-Gonzalez J, Esteban-Cornejo I, Cadenas-Sanchez C, Migueles JH, Molina-Garcia P, RodriguezAyllon M, Henriksson P, Pontifex MB, Catena A, Ortega FB: Physical Fitness, Physical Activity, and the Executive Function in Children with Overweight and Obesity. J Pediatr 2019, 208:50-56 e51. https://doi.org/10.1016/j.jpeds.2018.12.028

34. Hansen DM, Herrmann SD, Lambourne K, Lee J, Donnelly JE: Linear/nonlinear relations of activity and fitness with children's academic achievement. Medicine and science in sports and exercise 2014, 46(12):2279-2285. https://doi.org/10.1249/MSS.0000000000000362

35. Fang H, Quan M, Zhou T, Sun S, Liu W, Wang R, Chen P: Longitudinal Study on Trajectories of Physical Activity and Its Effect on Physical Fitness in Children. China Sport Sci 2018, 38(06):44-52. https://doi.org/10.16469/j.css.201806005

36. Buttelmann F, Karbach J: Development and Plasticity of Cognitive Flexibility in Early and Middle Childhood. Frontiers in psychology 2017, 8:1040. https://doi.org/10.3389/fpsyg.2017.01040

37. Chaddock L, Erickson KI, Prakash RS, VanPatter M, Voss MW, Pontifex MB, Raine LB, Hillman CH, Kramer AF: Basal ganglia volume is associated with aerobic fitness in preadolescent children. Dev Neurosci 2010, 32(3):249-256. https://doi.org/10.1159/000316648

\section{Figures}



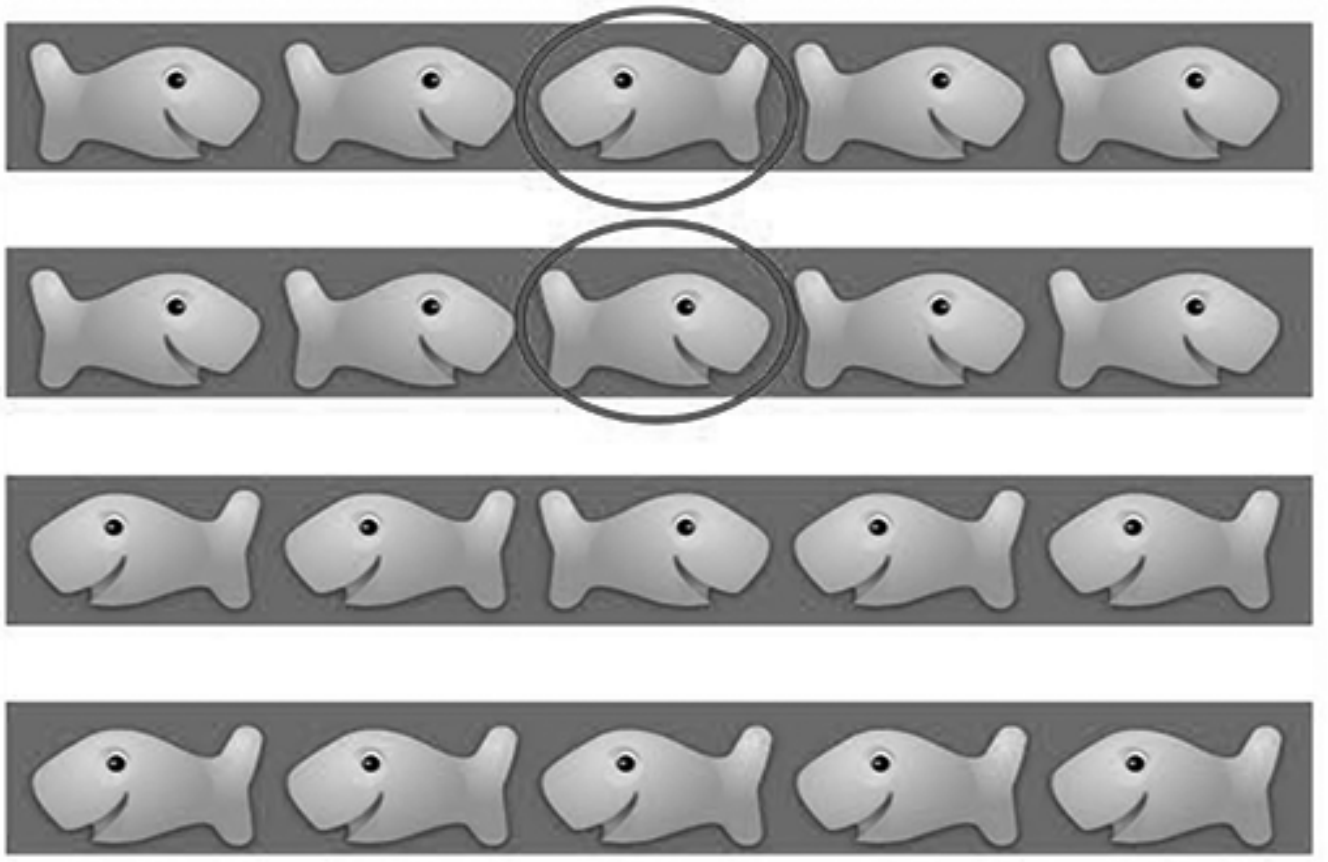

Figure 1

Fish Flanker Task

Preschool children in the second grade of kindergarten $(n=128)$

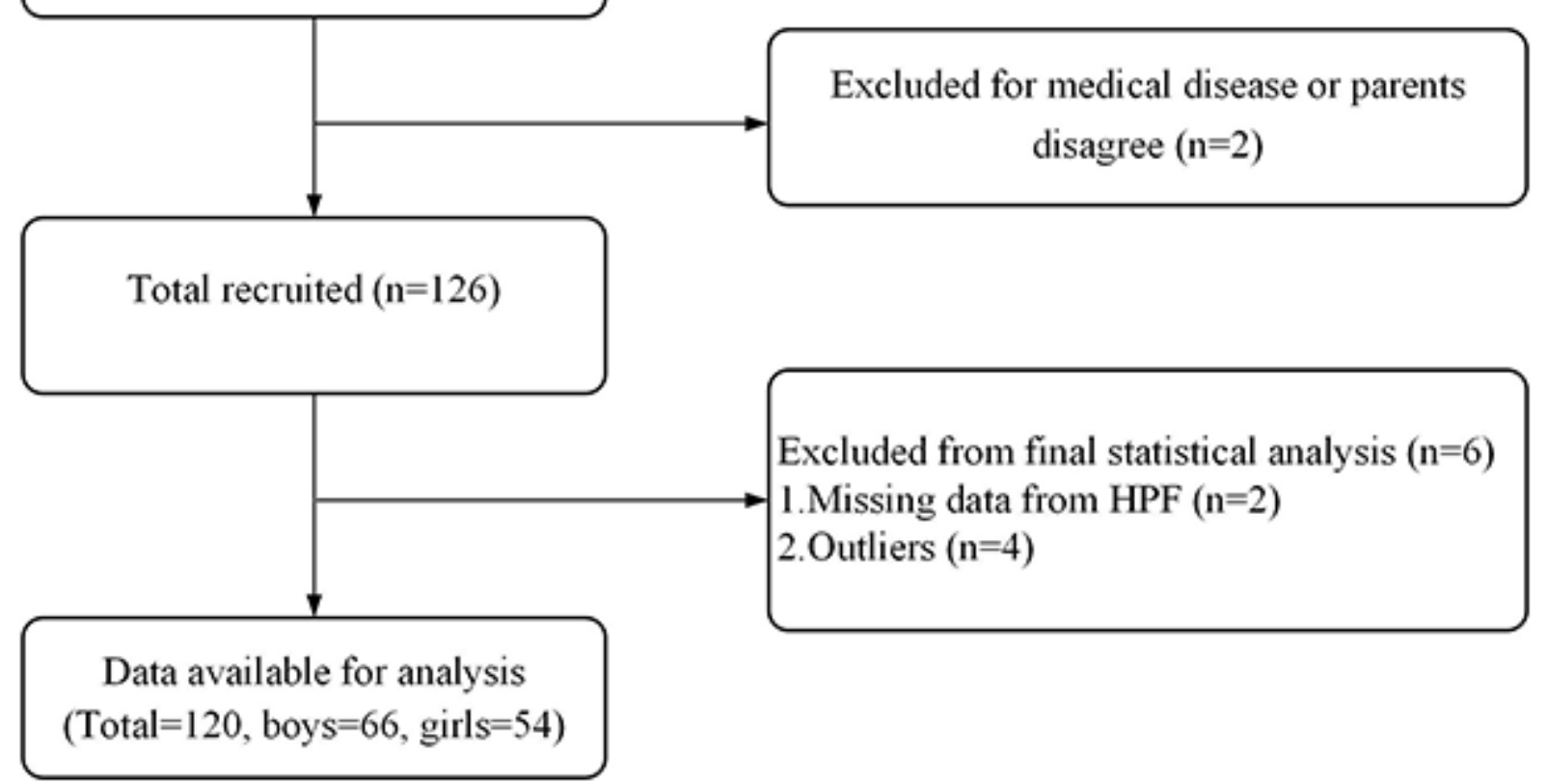

Figure 2

Flow of the participants screening in this study 


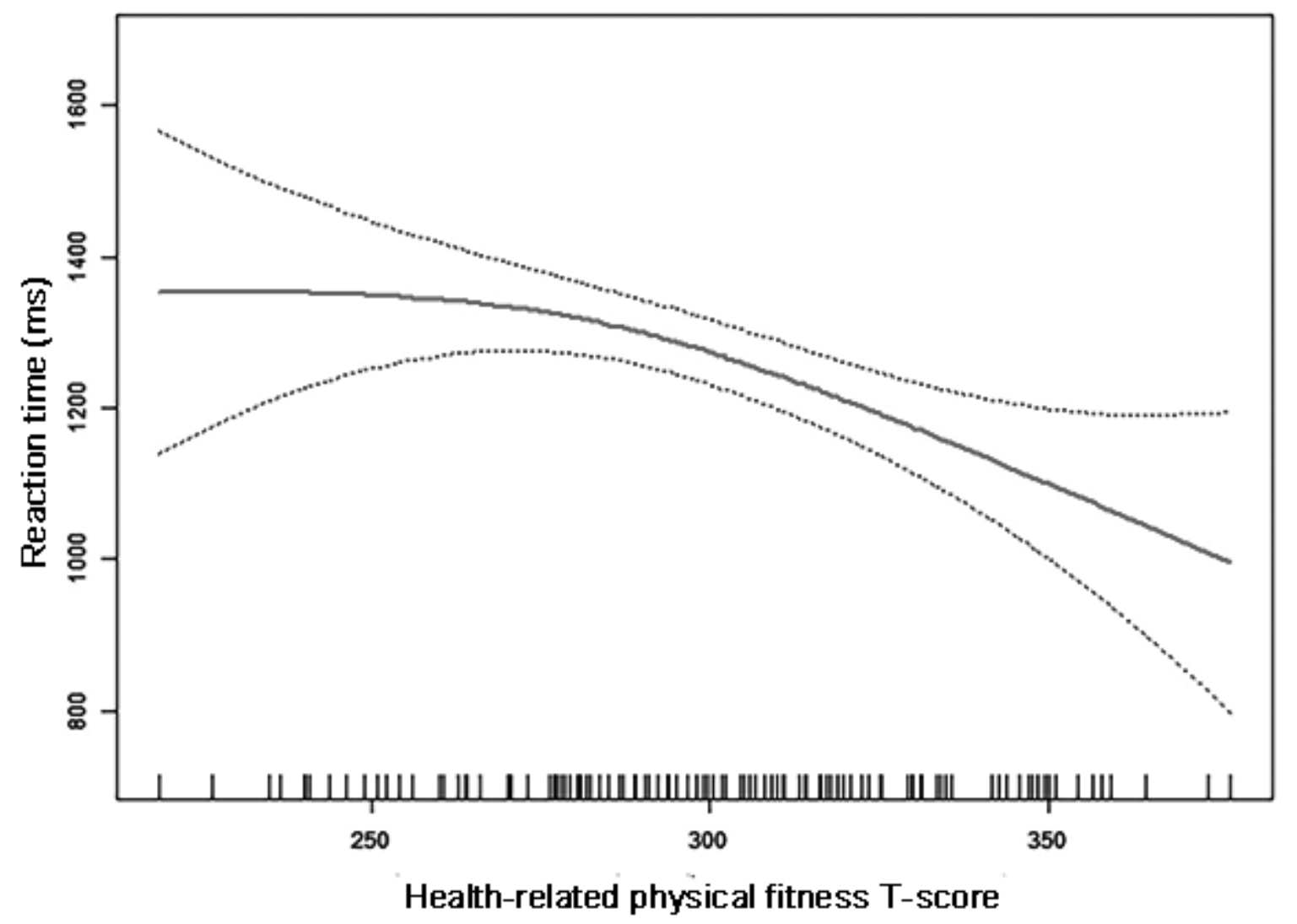

Figure 3

Association between HPFT and RT. The middle solid line shows the fitted curves, and the dot lines show the $95 \% \mathrm{Cl}$ after adjusting for age, sex, mother's education, and household income. 